\title{
"Buy Online, Pick Up in Store" under Fit Uncertainty: To Offer or Not to Offer
}

\author{
Huijing Li, ${ }^{1,2}$ Shilei Yang, ${ }^{1}$ Haiyan Kang $\mathbb{D}^{3,4}$ and Victor Shi ${ }^{5}$ \\ ${ }^{1}$ School of Business Administration, Southwestern University of Finance and Economics, Chengdu, China \\ ${ }^{2}$ School of Business, Guizhou Education University, Guiyang, China \\ ${ }^{3}$ Faculty of Business Administration, Jiangxi University of Finance and Economics, Nanchang, China \\ ${ }^{4}$ Faculty of Business Administration, Shanghai Business School, Shanghai 200235, China \\ ${ }^{5}$ Lazaridis School of Business and Economics, Wilfrid Laurier University, N2L 3C5, Waterloo, ON, Canada \\ Correspondence should be addressed to Haiyan Kang; 21090126@sbs.edu.cn
}

Received 2 May 2020; Accepted 28 May 2020; Published 4 July 2020

Guest Editor: Lei Xie

Copyright (c) 2020 Huijing Li et al. This is an open access article distributed under the Creative Commons Attribution License, which permits unrestricted use, distribution, and reproduction in any medium, provided the original work is properly cited.

Retailers offer BOPS (Buy Online, Pick Up in Store) service to improve consumers shopping experience. However, this greatly increases the decision complexity for retailers and consumers. For consumers, whether to purchase online or from a store with the BOPS service is a complex decision. This is especially true when the product has fit uncertainty. That is, consumers are uncertain about product fitness before using it. Also, their store visit cost can be heterogeneous and follows some distribution function. For a retailer, it needs to jointly optimize multiple decisions including the convenience degree of BOPS. To help the retailer develop the jointly optimal decisions, we first build a mathematical model where the retailer sells the product through online and store channel and analyzes the possible effects of BOPS. We find that the retailer should offer BOPS when the channel cost ratio (ratio of shipment fee divided by average store visit cost) is large enough. Through numerical studies, we show that the ratio of profit offering BOPS divided by the benchmark increases with the probability of product fit, shipment fee, and the convenience degree of BOPS. We then consider the case where the convenience degree of BOPS is also a decision itself. We find the optimal convenience degree of BOPS increases along with the average store visit cost and the probability of product fit. When the cost factor of offering the convenience for BOPS is larger than a threshold, the retailer should never offer BOPS.

\section{Introduction}

Nowadays, consumers can shop over multiple retailing channels, such as brick-and-mortar stores, online stores, mobile stores, and even social network platforms. Different channels have different advantages, and strategic consumers tend to exploit these channels together to buy the right product and enjoy better shopping experience. For instance, about $30 \%$ of consumers are willing to use one channel for searching product information and buy at another channel [1]. To make consumers enjoy the seamless shopping experience, omnichannel retailing strategy has been adopted by many retailers. For example, about $40 \%$ retailers use three or more channels to sell products and about $42 \%$ operate with two channels [2]. Omnichannel retailing is a strategy in which all of the channels, such as store, online channel, mobile channel, and social networks, are integrated so that the customers can use the channels seamlessly and enjoy a better customer experience [3].

As one way of integrated order fulfillment in the omnichannel, the BOPS (Buy Online, Pick Up in Store) has been offered by the many retailers such as Target, Walmart, and Tesco. Consumers should pay the shipment fee if they choose to buy online and use home delivery service, or pay no fee if picking up in local stores. Some retailers such as Tesco also offer some convenience for the BOPS customers, such as drive-through service where shoppers drive to the store and take the goods without getting out their cars. There is a tendency that consumers adopt the BOPS service due to the free pickup and convenience of BOPS. About $42 \%$ of 
Internet users respond that the BOPS is appealing [4] and BOPS is used by more consumers, for example, $30 \%$ of Target.com's online orders were fulfilled in stores [5]. Recently, there are several studies on the effect of BOPS. The total demand will increase due to cross-selling effect and channel shift effect [6], and the profit will increase under some conditions [7-10]. Meanwhile, BOPS usage will improve the frequency and amount of consumer purchases [11].

However, the existing literature fail to consider different product types, such as books or clothes. Books are more standardized products than clothes, which means consumers need to touch or try on before buying clothes than books due to fit uncertainty. Fit uncertainty is defined as the extent that consumers cannot decide whether the product fits before using it [12]. Fitness is a critical component for consumers shopping experiences, especially for nonstandardized products such as clothes and shoes. To lower the fit uncertainty, consumers prefer making physical purchases to buying online, especially when considering the product returns are costly to both consumers and retailers [13]. Some strategic consumers may visit the physical store first and then shop online and this will bring a new problem which is called search shopping phenomenon [14]. Search shopping phenomenon makes the consumer's search cost higher. The retailers have tried many measures to lower this cost and make better consumer satisfaction, such as virtual try-on [15], free samples [16], and BOPS [6]. For example, Uniqlo, which is a Japanese clothing brand, offers BOPS for the consumers who buy clothes though Alibaba's e-commerce platforms including Taobao and Tmall.

Different product types may affect the consumers' willingness and frequency to use BOPS. According to retail and e-commerce [4], electronics are the most popular goods that respondents were willing to purchase through BOPS, but the fresh prepared meals and groceries stood out as the least appealing categories. How should retailers offer BOPS for different types of products from those with more fit uncertainty to ones with less fit uncertainty? How will fit uncertainty affect the effect of BOPS? Research studies are needed to examine the effect of BOPS on different types of product $[7,17]$. Motivated by the above observations, we set out to study the effect of BOPS for the different product types with fit uncertainty. Hence, in this paper, we focus on the following research questions:

(1) How does the BOPS service affect the demand and profitability for goods with fit uncertainty?

(2) Should the retailer offer the BOPS service on goods with high fit uncertainty?

(3) How do the level of fit uncertainty and other shopping cost affect the retailer's performance?

To address these questions, a benchmark model that a retailer who operates dual channels without BOPS service is first constructed. The effect of BOPS from the perspective of the retailer is analyzed. The model is later extended to optimize the convenience degree of BOPS. We show that the retailers should be conscious to offer the BOPS for the goods with fit uncertainty. We identify that the retailer should offer BOPS when the channel cost ratio (the shipment fee divided by the average store visit cost) is high enough. The total demand will increase due to channel shift effect that consumers switch to BOPS from store channel and generate some new demand. It is interesting to find that the retailer's profit ratio increases with fit uncertainty.

The remainder of this paper is organized as follows. The related literature is reviewed in Section 2. The model of benchmark case without BOPS is introduced in Section 3. In Section 4, the detailed analysis of BOPS service is presented. In Section 5, the optimizing convenience degree of BOPS service is discussed. Finally, the implications and limitations of this research are concluded in Section 6.

\section{Relevant Literature}

BOPS is related to the integration between online and offline channels, where the online shopping behavior interacts with the offline store picking up experience. Our work is primarily related to three streams of research: dual-channel strategy, BOPS service, and fit uncertainty. We discuss each of these streams as follows.

Research on dual channels focuses on retailers' performance from different aspects such as product availability information [18], channel equilibrium structure [19], production assortment and delivery time design [20], channel integration [21, 22], and fulfillment service contracts [23]. Some studies analyze the dual-channel strategy from manufacturers' perspectives and focus on the channel conflict $[24,25]$ or channel coordination [26, 27]. The new online channel is used to compete with the independent retailer and improve the profit by the manufacturer [24]. Manufacturer redesigns channel service level to compete with retailers and the dual-channel strategy brings increased competition among the supply chain [25]. To achieve winwin purposes, manufacturers can design the channel coordination contracts to find the channel-adding Pareto zone and contract-implementing Pareto zone [26]. Manufacturers can also design the service-cost sharing contract when manufacturer's online channel free rides the retailer's presales services [27]. Similar to adding a new channel, BOPS service is a new choice for the consumers and may also bring the channel cannibalization problem. But BOPS is a way of integrating the existing channels under the omnichannel strategy [28], and offering BOPS is essentially different from adding a new channel.

Based on the cross-channel integration such as integrated price and assortment [7], BOPS is the most common integrated order fulfillment in the omnichannel strategy [29]. Researchers examine the contributing factors that affect the consumers adopting BOPS [17] and the effects of BOPS on the performance [6-10, 30]. Gallino et al. [6] use sales data and explain why the store demand may increase and the online demand decrease. Mahar et al. [30] optimize a set of pickup and return locations to reduce the cost of the retailer. Gao and $\mathrm{Su}$ [8] consider product availability and build a newsvendor model to analyze the effect of BOPS with crossselling. The authors build a consumer choice model and 
conclude that when the operation cost is low enough, the profit of the retailer will increase after offering BOPS, but there exists a channel cannibalization problem. Jin et al. [9] find the BOPS service area and compare the performance of BOPS with the ROPS (Reserve Online Pick Up and Pay in Store) from a retailer's point of view. Shi et al. [10] study the effect of BOPS with preorders when both informed and uninformed consumers exist. As the research progressed, the influence of BOPS on consumers' purchasing behavior has also attracted the attention of scholars. By collecting and analyzing consumers' bulk purchase data, Song et al. [11] find that BOPS usage has a significant impact on increasing the frequency and amount of consumer purchases. However, these researchers consider standardized products without fit uncertainty. Little research has built analytic models to study the effect of BOPS on nonstandardized products with fit uncertainty.

There is much research on the issue of fit uncertainty. As one type of information asymmetry problem, fit uncertainty can result in problems such as customer dissatisfaction [12], product returns [13, 31, 32], and search shopping phenomenon $[14,33,34]$. Retailers can employ fit uncertainty mitigating strategies such as money-back guarantees [35-37], online reviews [38, 39], virtual try-on [15], and free samples [16]. In general, reducing product fit uncertainty will improve consumer's purchase size and loyalty [40]. Some research works study the optimal pricing [41], promotion [42], and retailer shelf layout [43] to deal with the fit uncertainty problem. Our study focuses on the effect of product fit uncertainty on BOPS service.

\section{Benchmark Model without Offering BOPS Service}

We consider a retailer who sells products through an online channel and a store. Without BOPS, there are only two options: online channel where consumers buy directly online and the product is delivered home, and a store channel where consumers visit the store and purchase the product when it fits. The price $p$ in both channels is the same. Consumers are identical in terms of the product fit uncertainty $1-\delta$, where $\delta$ is called the fit probability where $0<\delta<1$. If consumers buy online, they should pay a fixed shipment fee $s$; if consumers buy in store, they incur a heterogeneous store visit cost $t$, which is uniformly distributed between 0 and $2 \bar{t}$ with an average positive store visit cost of $\bar{t} . v$ is the product value when it fits and is assumed large enough to ensure the utility of all channels is nonnegative. However, the product value is zero while it does not fit.

As shown in Figure 1, consumers may go to the store and buy the product only when it fits. Consumers may also buy directly through the online channel but undertake the shipment fee and the risk of fit uncertainty. The consumer's outcome is given by

$$
\begin{cases}v-p-t, & \text { travel to store and find the product fit, } \\ -t, & \text { travel to store and find the product unfit } \\ v-p-s, & \text { buy online and find the product fit } \\ -p-s, & \text { buy online and find the product unfit. }\end{cases}
$$

Let $u_{s}$ and $u_{o}$ denote the expected utility of the store and online channel, respectively. We have $u_{s}=\delta(v-p)-t$ and $u_{o}=\delta v-p-s$.

Consumers will buy the product through online channel if $u_{o} \geq u_{s}$. Let $t_{o s}$ denote the value of $t$ at which a consumer is indifferent between purchasing online or from the store where $t_{O S}=(1-\delta) p+s$. As shown in Figure 2, we can find that consumers who buy online must have higher store visiting cost than those who choose to buy in store. Consumers with a higher $t\left(2 \bar{t}>t \geq t_{O S}\right)$ will buy the product online. To make the demand of online channel is nonnegative, it is reasonable to assume $t_{O S}$ is lower than $2 \bar{t}$, i.e., $p \leq(2 \bar{t}-s) /(1-\delta)$. Consumers with a lower $t\left(0<t<t_{O S}\right)$ will visit store and buy the product only if it fits. Hence, only $\delta$ proportion of store visit consumers will buy the product in store, and $1-\delta$ proportion of store visit consumers are lost and this part of consumers is called the lost demand.

Let $D_{O}$ and $D_{S}$ denote the demand of the online and store channels, respectively. The expect demand of store channel is $D_{S}=\delta t_{O S} / 2 \bar{t}$, and the demand of online channel is $D_{O}=\left(2 \bar{t}-t_{O S}\right) / 2 \bar{t}$. The total demand and profit in this benchmark model are expressed as $D$ and $\pi$, respectively. The retailer chooses a price $p$ to maximize its profit as follows:

$$
\max _{p} \pi(p)=\left(D_{O}+D_{s}\right) p
$$

Lemma 1. In the benchmark model without offering BOPS service, the retailer's optimal price is $\min ((2 \bar{t}-s(1-\delta)) /$ $\left.\left(2(1-\delta)^{2}\right),(2 \bar{t}-s) /(1-\delta)\right)$, and the demand is shown in Table 1.

Proof. See appendix.

\section{The Model with BOPS Service}

4.1. Consumers' Channel Choice. With the BOPS service available, consumers can make an order online and pick up the product from the store for free. Hence, consumers compare three choices before making a purchase decision: directly buying online, buying in store, or choosing BOPS. Following Cao et al. [7], when consumers adopt the BOPS service, the pickup cost will be less than the store visiting cost due to the convenience that the retailer offers to BOPS adopters. The pickup cost of BOPS and the convenience degree of BOPS are denoted as $\theta t$ and $1-\theta$, respectively, where $0<\theta<1$. Consumers' realized utility outcome from BOPS is given by 


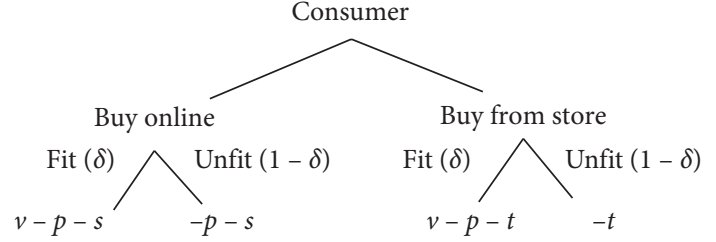

Figure 1: Consumers' decision tree and utility in benchmark.

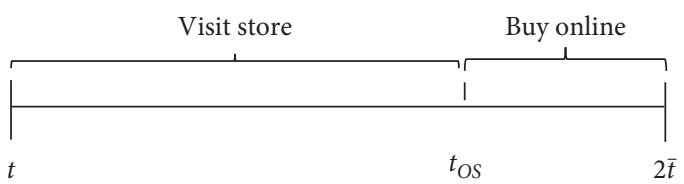

Figure 2: Consumers' channel choice in benchmark.

$\begin{cases}v-p-\theta t, & \text { adopt BOPS and find the product fit } \\ -p-\theta t, & \text { adopt BOPS and find the product unfit. }\end{cases}$

Let $u_{B}$ denote the expected utility of BOPS, then $u_{B}=\delta v-p-\theta t$. Let $t_{B S}$ and $t_{B O}$ be the value of $t$ at which BOPS service yields the same utility as store and online channel, respectively. These indifference values of $t$ can be shown as follows:

$$
\begin{aligned}
t_{B S} & =\frac{(1-\delta) p}{(1-\theta)}, \\
t_{B O} & =\frac{s}{\theta} .
\end{aligned}
$$

As shown in Figure 3, consumers with store visit cost between 0 and $t_{B S}$ will visit store and buy only if the product fits. Those with cost between $t_{B S}$ and $t_{B O}$ will adopt BOPS, while consumers whose store visiting cost is higher than $t_{B O}$ will buy from online channel and have the product delivered home.

The following lemma shows the conditions under which consumers choose the BOPS or buy online directly.

Lemma 2. In the model with BOPS service, (i) consumers choose BOPS service if $p \leq \min (((1-\theta) s) /((1-\delta) \theta)$, $(2 \bar{t}(1-\theta)) /(1-\delta))$, and (ii) consumers purchase online directly if $(s / \bar{t}) \leq 2 \theta$.

To understand when consumers choose the BOPS service, we can compare the utilities of store and online channel with BOPS, respectively. When $t$ is smaller than $t_{O S}$, the store channel is better than online channel. Hence, we compare the expected utility of the store channel with BOPS when $t \leq t_{\text {OS }}$. Consumers will adopt BOPS if the saving cost of visiting store $(1-\theta) t$ is larger than possible loss $(1-\delta) p$ due to fit uncertainty, which leads to $p \leq(1-\theta) t /(1-\delta)$. Since the consumer's possible highest store visit cost is $2 \bar{t}$, some consumers buy from BOPS $p \leq 2 \bar{t}(1-\theta) /(1-\delta)$. We then compare the online channel with the choice of BOPS when $t>t_{O S}$. Consumers will use BOPS if the saved shipment fee $s$ due to adopting BOPS is larger than the picking up cost $\theta t$, which leads to $s / \theta \geq t$. Since the consumer's lowest store visit cost is $t_{O S}$, some consumers buy through BOPS if $s / \theta \geq t_{\text {OS }}$. This is equal to that $p \leq(1-\theta) s /[(1-\delta) \theta]$. Hence, consumers adopt BOPS service if $p \leq \min (((1-\theta) s) /(1-\delta) \theta,(2 \bar{t}-s) /(1-\delta))$. Consumers will buy from online channel if and only if the picking up $\operatorname{cost} \theta t$ is larger than saving shipping fee $s$, i.e., $t \geq s / \theta$. Since the highest store visit cost is $2 \bar{t}$, some consumers buy online if $s / \bar{t} \leq 2 \theta$.

Based on Lemma 2, there are two new scenarios (B-O-S or B-S) compared with the benchmark. When $p \leq \min (((1-$ $\theta) s) /(1-\delta) \theta,(2 \bar{t}-s) /(1-\delta))$ and $s / \theta<2 \bar{t}$, all three types of consumers-BOPS shoppers (B), online shoppers $(\mathrm{O})$, and store shoppers $(\mathrm{S})$ - exist, which is called the B-O-S scenario. The consumers who buy directly online or store channel are called online shoppers and store shoppers, respectively. When $p \leq \min (((1-\theta) s) /(1-\delta) \theta,(2 \bar{t}-s) /(1-\delta))$ and $s / \theta>2 \bar{t}$, the consumer will not buy online and there are only two kinds of consumers-BOPS (B) and store shopper (S)existing. This is called the B-S scenario.

4.2. The Equilibrium Solution with BOPS. According to the purchasing behavior of three types of consumers, we can obtain the demand of each type in each scenario. The total demand and profit are expressed as $\widehat{D}$ and $\widehat{\pi}$ correspondingly. Let $D^{B-O-S}, \pi^{B-O-S}, D^{B-S}$, and $\pi^{B-S}$ denote the total demand and expected profit in scenarios B-O-S and B-S separately. The (expected) demands of store, online channel, and BOPS in scenarios B-O-S and B-S are denoted by $D_{S}^{B-O-S}, D_{O}^{B-O-S}, D_{B}^{B-O-S}, D_{S}^{B-S}$, and $D_{B}^{B-S}$ individually.

The retailer's demand of each channel in the B-O-S scenario is shown as follows: $D_{S}^{B-O-S}=\delta t_{O S} /(2 \bar{t}), D_{O}^{B-O-S}=$ $\left(2 \bar{t}-t_{B O}\right) /(2 \bar{t})$, and $D_{B}^{B-O-S}=\left(t_{B O}-t_{B S}\right) /(2 \bar{t})$. The retailer's demand of BOPS and store channel in the B-S scenario is $D_{B}^{B-S}=\left(2 \bar{t}-t_{B S}\right) /(2 \bar{t})$ and $D_{S}^{B-S}=\delta t_{B S} /(2 \bar{t})$, respectively.

We assume the retailer's cost of offering BOPS service is negligible. Considering the assumption of $p \leq(2 \bar{t}-s) /$ $(1-\delta)$, the condition for consumers to adopt BOPS service can be rewritten as $p \leq \min (((1-\theta) s) /(1-\delta) \theta,(2 \bar{t}-s) /$ $(1-\delta))$. Hence, the retailer's objective is to maximize its profit function with a price constraint:

$$
\begin{array}{ll}
\max _{p} & \hat{\pi}(p)=\widehat{D} p, \\
\text { s.t. } & p \leq \min \left(\frac{(1-\theta) s}{(1-\delta) \theta}, \frac{2 \bar{t}-s}{1-\delta}\right) .
\end{array}
$$

Lemma 3. The optimal scenario, price, and corresponding demand are shown in Table 2.

According to Lemma 2, for the B-O-S scenario, the price $\bar{t}(1-\theta) /(1-\delta)^{2}$ which makes the first-order derivative of profit function zero must be lower than $\min ((1-\theta) s /$ $\left.[(1-\delta) \theta], \bar{t}(1-\theta) /(1-\delta)^{2}\right)$, and $s / \theta$ must be smaller than $2 \bar{t}$. The validity condition of price $\bar{t}(1-\theta) /(1-\delta)^{2}$ in B-O-S scenario is $\theta /(1-\delta)<s / \bar{t}<2 \theta$. If the price $\bar{t}(1-\theta) /(1-\delta)^{2}$ is invalid, the optimal price should be the boundary price. 
TABLE 1: The optimal price, demand, and profit in the benchmark model.

\begin{tabular}{lccc}
\hline$\delta$ & $s / \bar{t}$ & Optimal price & Total demand \\
\hline$(0,1 / 2]$ & $(0,(2-4 \delta) /(1-\delta)]$ & $(2 \bar{t}-s(1-\delta)) /\left(2(1-\delta)^{2}\right)$ & $(2 \bar{t}-s(1-\delta)) / 2 \bar{t}$ \\
$(0,1 / 2]$ & $((2-4 \delta) /(1-\delta), 2]$ & $(2 \bar{t}-s) /(1-\delta)$ & $\delta$ \\
$(1 / 2,1)$ & $(0,2]$ & $(2 \bar{t}-s) /(1-\delta)$ & $\delta$ \\
\hline
\end{tabular}

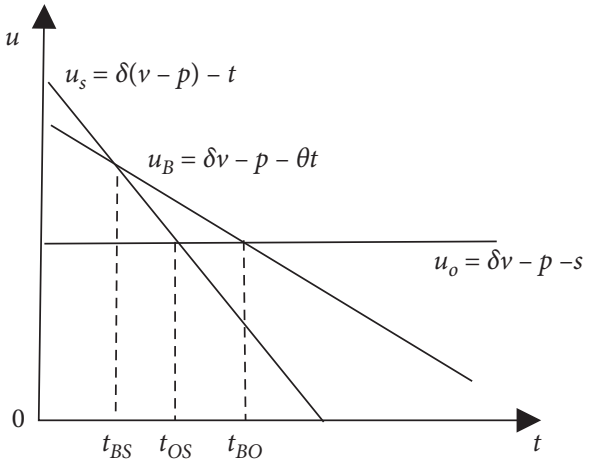

FIGURE 3: Consumers' utility function when offered BOPS.

So, the best prices and the corresponding conditions are shown in Table 2.

According to Balakrishnan et al. [44], the relative cost ratio $s / \bar{t}$ is referred as the channel cost ratio (CCR). Lemma 3 has shown that the optimal channel strategy is determined by the CCR. Low CCR, i.e., $s / \bar{t}<\theta /(1-\delta)$, implies that the shipment fee is very low compared with the average store visit cost and BOPS service does not have too much advantage. Consumers will buy from the online and store channel but will not adopt BOPS. When CCR is neither low nor high, i.e., $\theta /(1-\delta)<s / \bar{t}<2 \theta$ for $0<\delta<1 / 2$, the saved shipment fee is relatively high compared with average picking up cost. The advantage of BOPS is so obvious that there are more and more new consumers adopting it. When CCR is high, i.e., $s / \bar{t}>2 \theta$, all of the consumers will not buy from online. Only two options are existing (BOPS and store channel).

In the following sections, we will discuss the effect of BOPS through comparing with the benchmark.

4.3. The Effect of BOPS. Through comparing the profit, demand, and price after offering BOPS with the benchmark, we can get the following proposition.

\section{Proposition 1}

(i) When $0<\delta \leq(\sqrt{1-\theta} / 2)$, the retailer provides BOPS service to consumers for $(s / \bar{t}) \geq 2(1-\sqrt{1-\theta}) /(1-\delta)$

(ii) When $\sqrt{1-\theta} / 2<\delta \leq 1 / 2$, the retailer provides BOPS service to consumers for $s / \bar{t} \geq(4 \delta(1-\delta)-(1-\theta)) /$ $(2 \delta(1-\delta))$

(iii) When $(1 / 2)<\delta \leq 1$, the retailer provides BOPS service to consumers for $(s / \bar{t}) \geq 2 \theta$

As shown in Figure 4, the retailer should offer BOPS when CCR is higher than a threshold value. Meanwhile, we can also find the threshold value of CCR increases along with fit probability $\delta$ (for the $\delta$ smaller than 1/2) and the picking up cost factor $\theta$.

High CCR implies that BOPS is advantageous and more and more new consumers would choose it. As a result, the total demand increases, but the demand of store channel decreases. The profit is higher than that under the benchmark model due to the increased total demand.

Note that there is an important difference between the two purchase processes (buy from store directly vs. BOPS and online channel directly). As shown in Figure 5, when consumers choose to visit store firstly, only $\delta$ percent of consumers is translated to the final demand. But all of the consumers who buy online and BOPS are translated into final demand. After offered BOPS, a proportion of consumers who visit the store in the benchmark model is induced to buy though BOPS. The lost demand decreases and the total demand increases compared with the benchmark.

\subsection{Numerical Studies}

Numerical study 1: we explore the joint impact of shipment fee $s$ and the probability of product fit $\delta$ on the profit ratio $\hat{\pi} / \pi$, which is shown in Table 3 and plotted in Figure 6. The following parameters are used: $\bar{t}=0.6$ and $\theta=0.4$. From Figure 6 , we can find that the profit ratio is bigger than one when the CCR is large enough and the retailer should offer BOPS then. For example, for $\delta=0.4$, the retailer should offer BOPS if $s$ is bigger than 0.5 and CCR is larger than $5 / 6$. It is interesting to observe that higher fit uncertainty and shipment fee lead to a higher profit ratio.

Numerical study 2: the joint impact of average store visit $\operatorname{cost} \bar{t}$ and the picking up cost factor $\theta$ on the profit ratio is shown in Table 4 as well as plotted in Figure 7. The following parameters are used: $\delta=0.9$ and $s=10$. We can observe from Figure 7 that higher picking up cost factor $\theta$ and average store visit cost $\bar{t}$ lead to a lower profit ratio. When picking up cost factor is too high, for example $\theta=0.9$, the profit ratio is always lower than 1 . In this case, the retailer should not offer BOPS.

We will focus on the relationship between the profit ratio and the probability of product fit. As the probability of product fit increases, the lost demand decreases. Therefore, higher probability of product fit leads to lower profit ratio.

The sensitivity of $\delta, s, \bar{t}$, and $\theta$ has several important implications. First, everything else being equal, the higher the fit uncertainty and shipping fee, the more likely should the retailer offer BOPS. Second, the retailer can induce the consumers to adopt BOPS by offering more convenience such as drive-through service for BOPS shoppers. That may 
TABLE 2: The optimal scenario and the corresponding conditions.

\begin{tabular}{lcccc}
\hline$\delta$ & $s / \bar{t}$ & Scenario & Optimal price & Demand \\
\hline$(0,1 / 2]$ & $(0, \theta /(1-\delta)]$ & B-O-S & $((1-\theta) s) /((1-\delta) \theta)$ & $1-(s(1-\delta)) /(2 \theta \bar{t})$ \\
$(0,1 / 2]$ & $(\theta /(1-\delta),(1-2 \delta+\theta) /(1-\delta)]$ & B-O-S & $(\bar{t}(1-\theta)) /(1-\delta)^{2}$ & $1 / 2$ \\
$(0,1 / 2]$ & $((1-2 \delta+\theta) /(1-\delta), 2]$ & B-S & $(2 \bar{t}-s) /(1-\delta)$ & $1-((2 \bar{t}-s)(1-\delta)) /(2(1-\theta) \bar{t})$ \\
$(1 / 2,1)$ & $(0,2 \theta]$ & B-O-S & $((1-\theta) s) /((1-\delta) \theta)$ & $1-(s(1-\delta) / 2 \theta \bar{t})$ \\
$(1 / 2,1)$ & $(2 \theta, 2]$ & B-S & $(2 \bar{t}-s) /(1-\delta)$ & $1-(((2 \bar{t}-s)(1-\delta)) / 2(1-\theta) \bar{t})$ \\
\hline
\end{tabular}

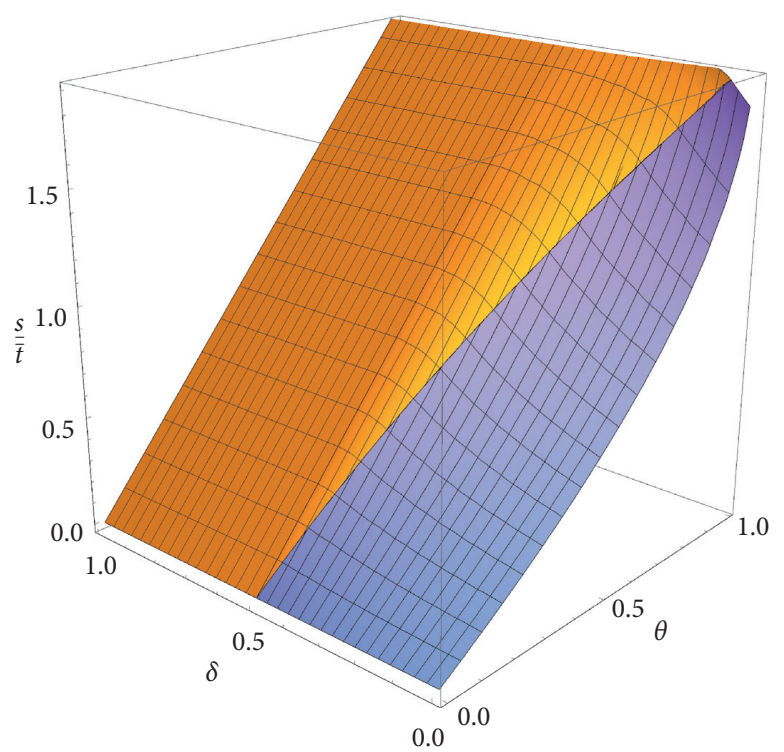

FIGURE 4: The threshold value of CCR above which the retailer should offer BOPS.

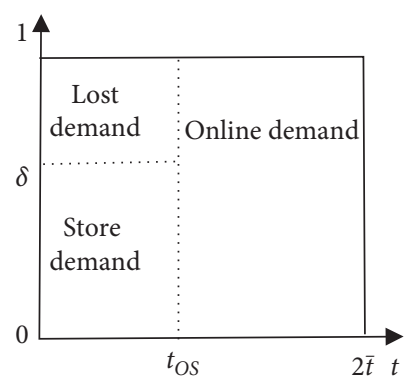

(a)

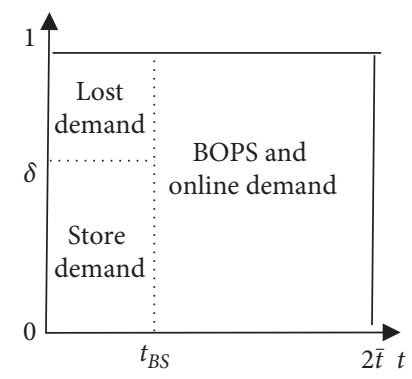

(b)

FIgURE 5: The demand allocation of benchmark (a) and the case with BOPS (b).

TABLE 3: The profit ratio $\hat{\pi} / \pi$ given $\bar{t}=0.6$ and $\theta=0.4$.

\begin{tabular}{|c|c|c|c|c|c|}
\hline$\delta$ & $s=0.4$ & $s=0.5$ & $s=0.6$ & $s=0.7$ & $s=0.8$ \\
\hline 0.1 & 1.22 & 1.54 & 1.98 & 2.66 & 3.75 \\
\hline 0.2 & 1.12 & 1.35 & 1.67 & 2.11 & 2.72 \\
\hline 0.3 & 1.02 & 1.20 & 1.42 & 1.71 & 2.04 \\
\hline 0.4 & 0.94 & 1.07 & 1.25 & 1.46 & 1.67 \\
\hline 0.5 & 0.87 & 1.03 & 1.17 & 1.31 & 1.44 \\
\hline 0.6 & 0.83 & 1.02 & 1.11 & 1.20 & 1.30 \\
\hline 0.7 & 0.80 & 1.01 & 1.07 & 1.13 & 1.19 \\
\hline 0.8 & 0.78 & 1.01 & 1.04 & 1.08 & 1.11 \\
\hline 0.9 & 0.76 & 1.00 & 1.02 & 1.03 & 1.05 \\
\hline
\end{tabular}




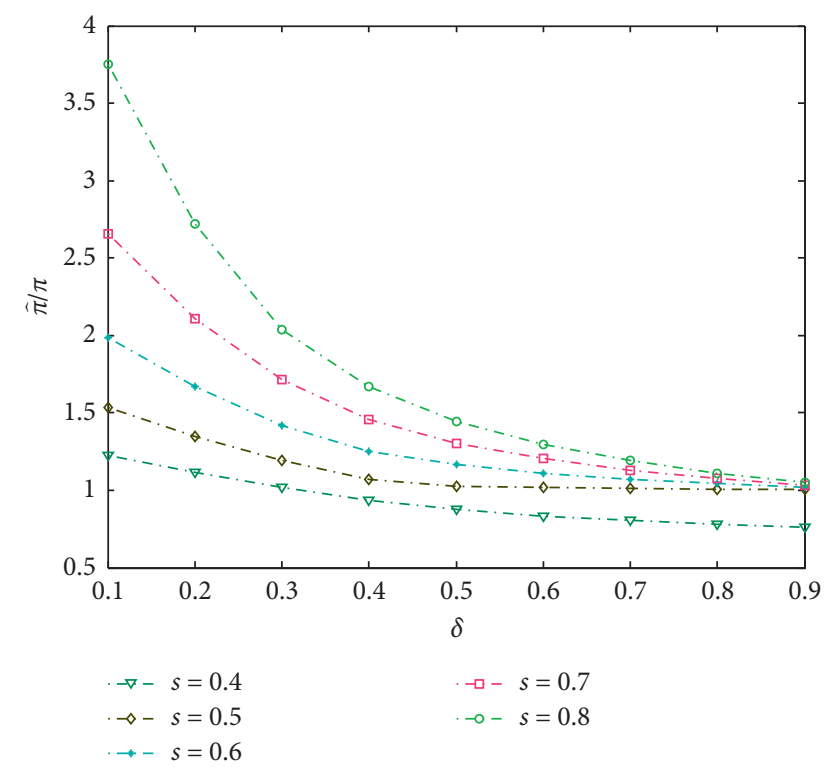

FIGURE 6: The effect of $s$ and $\delta$ on the profit ratio $\widehat{\pi} / \pi$.

TABLE 4: The profit ratio $\hat{\pi} / \pi$ given $\delta=0.4$ and $s=0.3$.

\begin{tabular}{lccccc}
\hline $\bar{t}$ & $\theta=0.1$ & $\theta=0.3$ & $\theta=0.5$ & $\theta=0.7$ & $\theta=0.9$ \\
\hline 0.2 & 2.08 & 1.96 & 1.75 & 1.25 & 0.42 \\
0.3 & 1.67 & 1.43 & 1.04 & 0.61 & 0.21 \\
0.4 & 1.46 & 1.16 & 0.83 & 0.50 & 0.17 \\
0.5 & 1.33 & 1.00 & 0.69 & 0.34 & 0.15 \\
0.6 & 1.25 & 0.97 & 0.58 & 0.28 & 0.08 \\
0.7 & 1.19 & 0.90 & 0.50 & 0.24 & 0.06 \\
0.8 & 1.14 & 0.83 & 0.44 & 0.21 & 0.06 \\
0.9 & 1.11 & 0.71 & 0.36 & 0.18 & 0.05 \\
1 & 1.09 & & & 0.16 & 0.04 \\
\hline
\end{tabular}

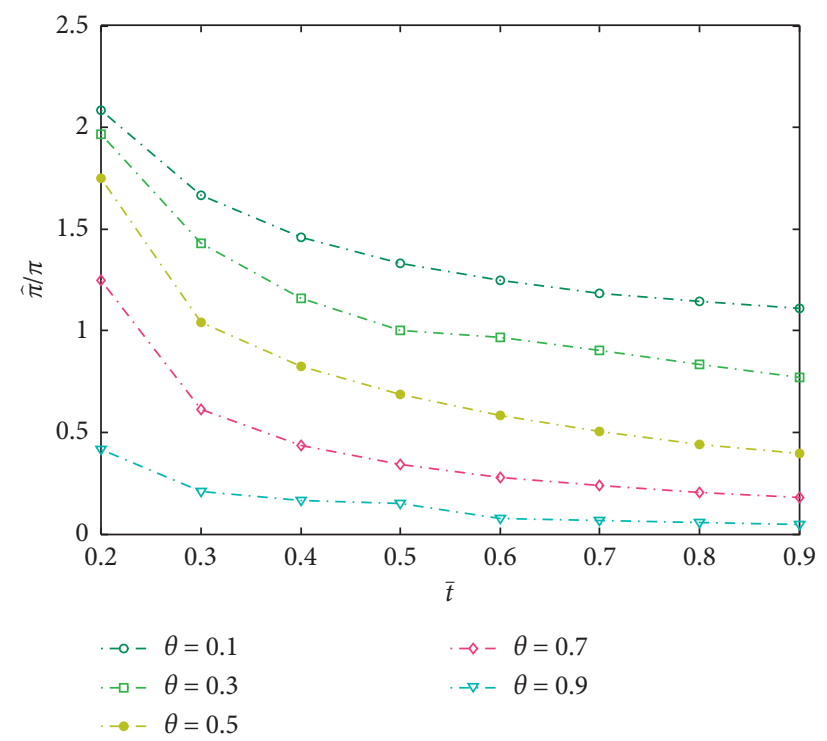

Figure 7: The effect of $\theta$ and $\bar{t}$ on the profit ratio $\hat{\pi} / \pi$. 
TABle 5: The optimal price and $\theta$.

\begin{tabular}{lccc}
\hline$\delta$ & $a$ & $s / \bar{t}$ & Optimal price and $\theta$ \\
\hline$(0,1 / 2]$ & $\left(0,\left(4 \bar{t}^{2}(4 \bar{t} \delta+s-s \delta-2 \bar{t})\right) /(s(2 \bar{t}-s)(1-\delta))\right)$ & $(0,(2-4 \delta) /(1-\delta))$ & $\left(\bar{t}^{2} /\left(2 a(1-\delta)^{4}\right), 1-\bar{t} /\left(2 a(1-\delta)^{2}\right)\right)$ \\
$(0,1 / 2]$ & $\left(0,\left(4 \bar{t}^{2}(4 \bar{t} \delta+s-s \delta-2 \bar{t})\right) /(s(2 \bar{t}-s)(1-\delta))\right)$ & $((2-4 \delta) /(1-\delta), 2)$ & $\left((2 \bar{t}-s) /(1-\delta), 1-\left((2 \bar{t}-s)^{2} / 2 a \bar{t}\right)^{1 / 3}\right)$ \\
$(0,1 / 2]$ & $\left(\left(4 \bar{t}^{2}(4 \bar{t} \delta+s-s \delta-2 \bar{t})\right) /(s(2 \bar{t}-s)(1-\delta)), 4 \bar{t}^{2} /(2 \bar{t}-s)\right)$ & $(0,2)$ & $\left(\bar{t}^{2} /\left(2 a(1-\delta)^{4}\right), 1-\bar{t} /\left(2 a(1-\delta)^{2}\right)\right)$ \\
$(0,1 / 2]$ & $\left(4 \bar{t}^{2} /(2 \bar{t}-s),+\infty\right)$ & $(0,2)$ & $((1-\theta) s /(1-\delta) \theta, 1)$ \\
$(1 / 2,1)$ & $\left(0,\left(4 \bar{t}^{2}(4 \bar{t} \delta+s-s \delta-2 \bar{t})\right) /(s(2 \bar{t}-s)(1-\delta))\right)$ & $(0,2)$ & $\left((2 \bar{t}-s) /(1-\delta), 1-\left((2 \bar{t}-s)^{2} / 2 a \bar{t}\right)^{1 / 3}\right)$ \\
$(1 / 2,1)$ & $\left(\left(4 \bar{t}^{2}(4 \bar{t} \delta+s-s \delta-2 \bar{t})\right) /(s(2 \bar{t}-s)(1-\delta)),+\infty\right)$ & $(0,2)$ & $((1-\theta) s /(1-\delta) \theta, 1)$ \\
\hline
\end{tabular}

TABLE 6: The feasible regions of $s / \bar{t}$ where the retailer should offer BOPS.

\begin{tabular}{lccc}
\hline Case no. & $\delta$ & $a$ & Feasible region of $s / \bar{t}$ \\
\hline III & $(0,1 / 2]$ & $\left(0,\left(4 \bar{t}^{2}(4 \bar{t} \delta+s-s \delta-2 \bar{t})\right) /(s(2 \bar{t}-s)(1-\delta))\right)$ & $(((2-4 \delta) /(1-\delta)), 2)$ \\
III & $(0,1 / 2]$ & $\left(\left(4 \bar{t}^{2}(4 \bar{t} \delta+s-s \delta-2 \bar{t})\right) /(s(2 \bar{t}-s)(1-\delta)), \bar{t} /\left(16 \delta^{2}(1-\delta)^{2}\right)\right)$ & $\left(\max \left((2(1-\delta)-\sqrt{\bar{t} / a}) /\left((1-\delta)^{2}\right), 0\right), 2\right)$ \\
& & $\left(\bar{t} /\left(16 \delta^{2}(1-\delta)^{2}\right), 4 \bar{t}^{2} /(2 \bar{t}-s)\right)$ & $\left(2-\left(\bar{t} /\left(8 a(1-\delta)^{3} \delta\right)\right), 2\right)$ \\
II & $(0,1 / 2]$ & $\left(4 \bar{t}^{2} /((2 \bar{t}-s)),+\infty\right)$ & $\varnothing$ \\
II & $(0,1 / 2]$ & $(0,16 \bar{t} / 27)$ & $(0,2)$ \\
I & $(1 / 2,1)$ & $\left(16 \bar{t} / 27,\left(4 \bar{t}^{2}(4 \bar{t} \delta+s-s \delta-2 \bar{t})\right) /(s(2 \bar{t}-s)(1-\delta))\right)$ & $(((\bar{t}(108 a-64 \bar{t})) / 54 a), 2)$ \\
III & $(1 / 2,1)$ & $\left(\left(4 \bar{t}^{2}(4 \bar{t} \delta+s-s \delta-2 \bar{t})\right) /(s(2 \bar{t}-s)(1-\delta)),+\infty\right)$ & $\varnothing$ \\
II & $(1 / 2,1)$ & & \\
\hline
\end{tabular}

be the main reason why Tesco and other grocery stores offer the drive-through service for BOPS shoppers [45].

\section{Extension: The Optimal Convenience Degree}

High convenience degree will incentivize more consumers to adopt the BOPS but also lead to higher costs. If we assume the retailer's cost of offering convenience for BOPS users is not negligible, the retailer should jointly determine the price and the convenience degree of BOPS. Then, the profit of the retailer is given by

$$
\begin{aligned}
& \max _{(p, \theta)} \quad \pi(p, \theta)=D p-\frac{a(1-\theta)^{2}}{2}, \\
& \text { s.t. } \quad p \leq \min \left(\frac{(1-\theta) s}{(1-\delta) \theta}, \frac{2 \bar{t}-s}{1-\delta}\right),
\end{aligned}
$$

where $a$ refers to a positive cost factor. $a(1-\theta)^{2} / 2$ is the cost of offering convenience for the BOPS adopters, which means the cost becomes higher as the convenience degree $1-\theta$ increases. Similar approaches to modeling service effort have been used extensively in the literature (see, e.g., Ofek et al. [31]).

5.1. The Profit and Equilibrium Solution with BOPS. Similar to Section 4, there are two scenarios (B-O-S or B-S) with BOPS offering. Setting up Lagrange Functions and using the KKT conditions to discuss each scenario, we can obtain the optimal price and $\theta$.

Lemma 4. The optimal price and $\theta$ are summarized in Table 5.

\subsection{The Effect of BOPS}

Proposition 2. The feasible regions of $s / \bar{t}$ in which the retailer should provide BOPS service to consumers are given in Table 6.

(I) When the cost factor a is sufficiently low, the retailer should always offer BOPS

(II) When the cost factor $a$ is sufficiently high, the retailer should never offer BOPS

(III) Otherwise, the retailer should offer BOPS when CCR is high enough

\section{Conclusion and Future Research}

In this paper, we built an analytic model where a retailer sells a product with fit uncertainty through online, store, or BOPS channels. The primary objective of this paper is to examine the effect of BOPS and the strategies of offering BOPS service from a retailer's point of view.

Our main results are as follows. Even if the cost of providing BOPS service is zero, the retailer should not offer BOPS fit when the CCR is low. This is because when the CCR is low, there are fewer consumers who would choose BOPS unless the retailer lowers the price, which leads to a lower profit. When the CCR is high, the total demand and the profit improve but BOPS will cannibalize the store channel. Hence, that retailer should be cautious about offering the BOPS when CCR is under a threshold value. The retailer needs to improve the convenience degree of BOPS and help consumers reduce the picking up cost. Another interesting result is that the higher likelihood of product fit will result in a lower profit ratio $\widehat{\pi} / \pi$. When the cost of offering convenience for BOPS users is not negligible, the retailer should offer BOPS only when the cost factor is not very high but CCR is high enough. It is better to offer a higher convenience degree of BOPS if the average store visit cost and the probability of product fit are high. 
There can be multiple directions for future research. First, in our paper, product return is not allowed. As consumer return is an important practice and the majority of retailers do allow consumers to return unfit products, future research might jointly consider the BOPS and product return. Second, in this paper, we limit ourselves to the case of a single retailer. As offering the BOPS service will impact retailer competition, it is worthwhile to investigate how BOPS may affect the competition of multiple retailers and their profits. Third, BOPS can be studied together with issues like manufacturer encroachment [46], supply chain design [47], and corporate social responsibility [48].

\section{Appendix}

\section{A. Proof of Lemma 1}

From $t_{O S} \leq 2 \bar{t}$, we can get $0<p \leq p_{0}=(2 \bar{t}-s) /(1-\delta)$ and $2 \bar{t}<s$.

The profit is $\prod=p\left(2 \bar{t}-p(1-\delta)^{2}+s \delta-s\right) / 2 t$.

$\partial^{2} \prod / \partial^{2} p=-(1-\partial)^{2} / \bar{t}<0$; when $\partial \Pi / \partial p=0$, we can get $p=(2 \bar{t}-s(1-\delta)) /\left(2(1-\delta)^{2}\right)=p_{2}$.

So the optimal price $p_{0}^{*}=\min \left(p_{2}, p_{0}\right)$. When $0<\delta<(1 / 2)$ and $0<(s / \bar{t})<(2-4 \delta) /(1-\delta), p_{2}<p_{0}$ and $p_{0}^{*}=p_{2}$. Otherwise, $p_{2}<p_{0}$ and $p_{0}^{*}=p_{0}$. Q.E.D

\section{B. Proof of Lemma 2}

We can get that the consumers cost $t_{1}<t \leq t_{0}$ and $t_{0}<t \leq t_{2}$ will adopt the BOPS.

So, the demand of BOPS exists when $t_{1} \leq 2 \bar{t}$ and $t_{1} \leq t_{0}$ or $t_{0} \leq t_{2}$

$2 \bar{t}-t_{1}=(2 \bar{t}(1-\theta)-p(1-\delta)) /(1-\theta)$. So when $2 \bar{t}(1-\theta) \geq p(1-\delta)$, which means $p \leq(2 \bar{t}(1-\theta)) /$ $((1-\delta)) \stackrel{\text { def }}{=} p_{5}, t_{1} \leq 2 \bar{t}$.

$t_{0}-t_{1}=(s(1-\theta)-p(1-\delta) \theta) /(1-\theta) ; t_{2}-t_{0}=(s(1-$ $\theta)-p(1-\delta) \theta) / \theta$. So when $s(1-\theta) \geq p(1-\delta) \theta$, which means $p \leq(1-\theta) s /(1-\delta) \theta \stackrel{\text { def }}{=} p_{3}, t_{1} \leq t_{0}$ and $t_{0} \leq t_{2}$.

The demand of BOPS exists when $t_{2}=(s / \theta) \leq 2 \bar{t}$, which means $(s / \bar{t})<2 \theta, t_{2} \leq 2 \bar{t}$. Q.E.D

\section{Proof of Lemma 3}

The profit is $\pi^{S}=p-\left(p^{2}(1-\delta)^{2}\right) /(2 \bar{t}(1-\theta)) \cdot \partial^{2} \Pi /$ $\partial^{2} p=-\bar{t}(1-\theta) /(1-\delta)^{2}<0$. When $\partial \Pi / \partial p=0$, we can get $p=\bar{t}(1-\theta) /(1-\delta)^{2}=p_{4}$. When $p_{4}$ is the optimal price, the condition of B-O-R scenario is $p_{4} \leq p_{3}$ and $(s / \theta) \leq 2 \bar{t}$. And $p_{4}-p_{3}=(1-\theta)(s(1-\delta)-\bar{t} \theta) /(1-\delta)^{2} \theta$. Hence, when $s(1-\delta)-\bar{t} \theta>0$, which means $s / \bar{t} \geq \theta /(1-\delta), p_{4} \leq p_{3}$. So the corresponding region of $\mathrm{B}-\mathrm{O}-\mathrm{R}$ scenario is $(\theta /(1-\delta)) \leq(s / \bar{t}) \leq 2 \theta$ and $0<\delta<(1 / 2)$.

When $p_{4}>p_{3}$, the optimal price is $p_{3}$. And the corresponding region of B-O-R scenario is $(s / \bar{t}) \leq 2 \theta$ when $\delta>(1 / 2)$ or $(s / \bar{t}) \leq \theta /(1-\delta)$ when $\delta<(1 / 2)$. Q.E.D

The condition of $\mathrm{O}-\mathrm{R}$ scenario can be obtained similarly.

\section{Proof of Proposition 1}

We prove Proposition 1 by 4 parts according to the value region of $\delta: 0<\delta<(1-\theta) /(2-\theta), \quad(1-\theta) /(2-\theta)<\delta<$ $(2-\theta) / 4,(2-\theta) / 4<\delta<(1 / 2)$, and $(1 / 2)<\delta<1$.

Part 1: $0<\delta<(1-\theta) /(2-\theta)$

When $\delta<(1-\theta) /(2-\theta)$, we can get $\theta /(1-\delta)<2 \theta<$ $(2-4 \delta) /(1-\delta)$

We will discuss the changes in profit, demand, and price in turn. First, let us discuss the change in profit. When $0<\delta<(1-\theta) /(2-\theta)$ and $s / \bar{t} \leq \theta /(1-\delta)$, we should compare $\pi^{B O R}\left(p_{3}\right)$ with $\pi\left(p_{2}\right)$ :

$$
\pi^{B O R}\left(p_{3}\right)-\pi\left(p_{2}\right)=-\frac{(s(1-\delta)(2-\theta)-2 \bar{t} \theta)^{2}}{8 \bar{t}(1-\delta)^{2} \theta^{2}}<0 .
$$

When $\theta /(1-\delta)<(s / \bar{t}) \leq(2-4 \delta) /(1-\delta)$, we should compare $\pi^{B O R}\left(p_{4}\right)$ with $\pi\left(p_{2}\right)$ :

$$
\pi^{B O R}\left(p_{4}\right)-\pi\left(p_{2}\right)=\frac{4 s \bar{t}(1-\delta)-s^{2}(1-\delta)^{2}-4 \bar{t}^{2} \theta}{8 \bar{t}(1-\delta)^{2}} .
$$

When $4 s \bar{t}(1-\delta)-s^{2}(1-\delta)^{2}-4 \bar{t}^{2} \theta<0$, which means $(s / \bar{t})<2(1-\sqrt{1-\theta}) /(1-\delta), \pi^{B O R}\left(p_{4}\right)<\pi\left(p_{2}\right)$.

When $(s / \bar{t})>2(1-\sqrt{1-\theta}) /(1-\delta), \pi^{B O R}\left(p_{4}\right)>\pi\left(p_{2}\right)$. The change in demand is discussed as follows:

$$
\begin{aligned}
D^{S}\left(p_{4}\right)-D_{0}\left(p_{2}\right) & =\frac{s(1-\delta)}{4 \bar{t}}>0, \\
D_{S 0}\left(p_{2}\right)-D_{S}^{B R}\left(p_{4}\right) & =D_{S 0}\left(p_{2}\right)-D_{S}^{B O R}\left(p_{4}\right)=\frac{s \delta}{4 \bar{t}}>0, \\
D_{O 0}\left(p_{2}\right)-D_{O}^{B O R}\left(p_{4}\right) & =\frac{s(1-\delta)(2-\theta)-2 \bar{t} \theta}{4 \bar{t}(1-\delta) \theta} .
\end{aligned}
$$

If $s(1-\delta)(2-\theta)-2 \bar{t} \theta>0$, i.e., $2 \delta /(1-\delta)(2-\theta)<(s / \bar{t})$, we can get $D_{\mathrm{O}}\left(p_{2}\right)>D_{O}^{B O R}\left(p_{4}\right)$.

Because $2 \delta /(1-\delta)(2-\theta)>2(1-\sqrt{1-\theta}) /(1-\delta)$, the demand of online channel will decrease when $2(1-\sqrt{1-\theta}) /(1-\delta)<(s / \bar{t})<2 \delta /(1-\delta)(2-\theta)$ but increase when $2 \delta /(1-\delta)(2-\theta)<(s / \bar{t})<(2-4 \delta) /(1-\delta)$.

We will discuss the change in price as follows:

$$
p_{4}-p_{2}=\frac{s(1-\delta)-2 \bar{t} \theta}{2(1-\delta)^{2}}, \quad \text { when } \frac{2 \theta}{(1-\delta)}<\frac{s}{\bar{t}}, p_{4}>p_{2} \text {. }
$$

Because $2 \theta /(1-\delta)>(2(1-\sqrt{1-\theta})) /(1-\delta)$, the price will decrease when $(2(1-\sqrt{1-\theta})) /(1-\delta)<(s / \bar{t})<2 \theta /$ $(1-\delta)$ but increase when $2 \theta /(1-\delta)<(s / \bar{t})<(2-4 \delta) /$ $(1-\delta)$.

Similarly, we can get the change in profit, demand, and price when $(2-4 \delta) /(1-\delta)<(s / \vec{t}) \leq 2$.

When $0<\delta<(1-\theta) /(2-\theta)$ and $(2-4 \delta) /(1-\delta)<$ $(s / \bar{t}) \leq 2$, we should compare $\pi^{B O R}\left(p_{4}\right)$ with $\pi\left(p_{0}\right)$ : 


$$
\pi^{B O R}\left(p_{4}\right)-\pi\left(p_{0}\right)=\frac{(s(1-\delta)-\bar{t}(1-2 \delta+\theta))^{2}}{2 t 8(1-\delta)^{2}(1-\theta)}>0 .
$$

So, we can get that when $0<\delta<(1-\theta) /(2-\theta)$, the retailer can get more profit than benchmark with offering BOPS service if $(s / \bar{t})>2(1-\sqrt{1-\theta}) /(1-\delta)$. Otherwise, the retailer should better not offer BOPS:

$$
\begin{aligned}
D^{S}\left(p_{4}\right)-D_{0}\left(p_{0}\right)= & \frac{1}{2}-\delta>0, \\
D_{S 0}\left(p_{0}\right)-D_{S}^{B R}\left(p_{4}\right)= & \frac{\delta(1-2 \delta)}{2(1-\delta)}>0, \\
p_{4}-p_{0}= & \frac{s(1-\delta)+\bar{t}(2 \delta-1-\theta)}{(1-\delta)^{2}}, \text { when } \\
& \frac{1-2 \delta+\theta}{(1-\delta)}<\frac{s}{\bar{t}}, p_{4}>p_{2} .
\end{aligned}
$$

Because when $(1-\theta) / 2<\delta, \quad(1-2 \delta+\theta) /(1-\delta)>$ $(2-4 \delta) /(1-\delta)$. When $(1-\theta) / 2<\delta<(1-\theta) /(2-\theta)$, the price will decrease if $(2-4 \delta) /(1-\delta)<(s / \bar{t})<(1-$ $2 \delta+\theta) /(1-\delta)$ but increase when $(1-2 \delta+\theta) /(1-\delta)$ $<(s / \bar{t})<2$. When $0<\delta<(1-\theta) / 2$, the price will increase.

The change in profit, demand, and price of other four parts can be obtained similarly.

\section{E. Proof of Lemma 4}

$\pi\left(p_{5}^{\prime}, \theta_{5}\right)-\pi\left(p_{3}^{\prime}, \theta_{3}\right)=\left(a(2 \bar{t}-s)(1-\delta)-4 \bar{t}^{2} \delta\right)^{2} / 8 a$ $\bar{t}^{2}(1-\delta)^{2} \geq 0$. So, the optimal strategy is $\left(p_{5}^{\prime}, \theta_{5}\right)$. $\pi\left(p_{4}^{\prime}, \theta_{4}\right)-\pi\left(p_{6}, \theta_{3}\right)=\left(\bar{t}^{2}+a(s-2 \bar{t})(1-\delta)^{2}\right)^{2} /$

$\left(8 a \bar{t}^{2}(1-\delta)^{4}\right) \geq 0$. So, the optimal strategy is $\left(p_{4}^{\prime}, \theta_{4}\right)$.

$\pi\left(p_{5}, \theta_{5}\right)-\pi\left(p_{3}, \theta_{3}\right) \geq 0$; so, we can get the optimal strategy.

\section{F. Proof of Proposition 2}

$$
\pi\left(p_{4}^{\prime}, \theta_{4}\right)-\pi\left(p_{2}\right)=\frac{\bar{t}^{3}-a(2 \bar{t}-s(1-\delta))^{2}(1-\delta)^{2}}{8 a \bar{t}(1-\delta)^{4}} .
$$

When $(2(1-\delta)-\sqrt{t / a}) /(1-\delta)^{2}<(s / \bar{t}), \quad \pi\left(p_{4}^{\prime}, \theta_{4}\right)>$ $\pi\left(p_{2}\right)$.

When $a<\bar{t} /\left(16 \delta^{2}(1-\delta)^{2}\right), \quad(2(1-\delta)-\sqrt{t / a}) /(1-$ $\delta)^{2}<(2-4 \delta) /(1-\delta)$. The profit will increase for $(2(1-\delta)-\sqrt{\bar{t} / a}) /(1-\delta)^{2}<(s / \bar{t}):$

$$
\pi\left(p_{4}^{\prime}, \theta_{4}\right)-\pi\left(p_{0}\right)=\frac{\bar{t}^{2}+8 a \delta(1-\delta)^{3}(s-2 \bar{t})}{8 a(1-\delta)^{4}} .
$$

When $2-\left(\bar{t} /\left(8 a(1-\delta)^{3} \delta\right)\right)<(s / \bar{t}), \pi\left(p_{4}^{\prime}, \theta_{4}\right)>\pi\left(p_{0}\right)$; the profit will increase for $\max \left((2(1-\delta)-\sqrt{\bar{t} / a}) /(1-\delta)^{2}\right.$, $(2-4 \delta) /(1-\delta))<(s / \bar{t})$ :

$$
\pi\left(p_{5}^{\prime}, \theta_{5}\right)-\pi\left(p_{2}\right)=\frac{16 \bar{t}^{3} \delta^{2}-a(2 \bar{t}-s(1-\delta))^{2}}{8 a \bar{t}(1-\delta)^{2}} .
$$

When $a<\left(16 \bar{t}^{3} \delta^{2}\right) /(2 \bar{t}-s(1-\delta))^{2}, \pi\left(p_{5}^{\prime}, \theta_{5}\right)>\pi\left(p_{2}\right)$ :

$$
\pi\left(p_{5}^{\prime}, \theta_{5}\right)-\pi\left(p_{0}\right)=\frac{\delta\left(a(s-2 \bar{t})(1-\delta)+2 \bar{t}^{2} \delta\right)}{a(1-\delta)^{2}} .
$$

When $2-\bar{t} /\left(8 a(1-\delta)^{3} \delta\right)<(s / \bar{t}), \pi\left(p_{5}^{\prime}, \theta_{5}\right)>\pi\left(p_{0}\right)$ :

$$
\begin{aligned}
& \pi\left(p_{5}^{\prime}, \theta_{3}\right)-\pi\left(p_{2}\right)=-\frac{a(s-2 \bar{t})^{2}(1-\delta)^{2}+\bar{t}(s-2 \bar{t}-s \delta+4 \bar{t} \delta)^{2}}{8 \bar{t}^{2}(1-\delta)^{2}}<0, \\
& \pi\left(p_{5}^{\prime}, \theta_{3}\right)-\pi\left(p_{0}\right)=-\frac{a(s-2 \bar{t})^{2}}{8 \bar{t}^{2}}<0 .
\end{aligned}
$$

\section{Data Availability}

Data will be available upon request.

\section{Conflicts of Interest}

The authors declare that they have no conflicts of interest.

\section{Acknowledgments}

This research was supported by the National Natural Science Foundation of China (71871186 and 71471150), the Project for Guizhou Provincial Department of Education (2018qn09), and the Fundamental Research Funds for the Central Universities (JBK18JYT02 and JBK1902009). Kang's research was supported by Application-Oriented Undergraduate Majors of Shanghai Universities (Round 4; \#20) and the National Social Science Fund of China (\#18BGL115).

\section{References}

[1] B. Yellavali, D. Holt, and A. Jandial, "Retail Multi-Channel Integration, Delivering a Seamless Customer Experience," Infosys Technologies Ltd, Dallas, TX, USA, 2004.

[2] DMA, "Multichannel Marketing Report," The Direct Marketing Association, New York, NY, USA, 2005.

[3] D. Rigby, "The future of shopping," Harvard Business Review, vol. 89, no. 12, pp. 65-76, 2011.

[4] Retail \& Ecommerce, "Why retailers should offer buy online, pick up in-store," Retail \& Ecommerce, vol. 8, 2015.

[5] L. Chao, "Target Says Online Sales Surge Tied to Store Inventories; with Digital Sales up 34\% Last Quarter, the Retailer Says in-Store Pickups were Central to Both e Commerce and Store Sales Growth,"Wall Street Journal, New York, NY, USA, 2016.

[6] S. Gallino and A. Moreno, "Integration of online and offline channels in retail: the impact of sharing reliable inventory availability information," Management Science, vol. 60, no. 6, pp. 1434-1451, 2014.

[7] J. Cao, K. C. So, and S. Yin, "Impact of an "online-to-store" channel on demand allocation, pricing and profitability," European Journal of Operational Research, vol. 248, no. 1, pp. 234-245, 2016.

[8] F. Gao and X. Su, "Omni-channel retail operations with buyonline-and-pickup-in- store," Management Science, vol. 63, no. 8, pp. 2478-2492, 2016. 
[9] M. Jin, G. Li, and T. C. E. Cheng, "Buy online and pick up instore: design of the service area," European Journal of Operational Research, vol. 268, no. 2, pp. 613-623, 2018.

[10] X. Shi, C. Dong, and T. C. E. Cheng, "Does the buy-onlineand-pick-up-in-store strategy with pre-orders benefit a retailer with the consideration of returns?" International Journal of Production Economics, vol. 206, pp. 134-145, 2018.

[11] P. Song, Q. Wang, H. Liu, and Q. Li, "The value of buy-onlineand-pickup-in-store in omni-channel: evidence from customer usage data," Production and Operations Management, vol. 29, no. 4, pp. 995-1010, 2019.

[12] Y. Hong and P. A. Pavlou, "Product fit uncertainty in online markets: nature, effects, and antecedents," Information Systems Research, vol. 25, no. 2, pp. 328-344, 2014.

[13] T. Xiao and J. Shi, "Consumer returns reduction and information revelation mechanism for a supply chain," Annals of Operations Research, vol. 240, no. 2, pp. 661-681, 2016.

[14] J. Shin, "How does free riding on customer service affect competition?" Marketing Science, vol. 26, no. 4, pp. 488-503, 2007.

[15] J. Kim and S. Forsythe, "Adoption of virtual try-on technology for online apparel shopping," Journal of Interactive Marketing, vol. 22, no. 2, pp. 45-59, 2008.

[16] D. R. Bell, S. Gallino, and A. Moreno, "How to win in an Omni-channel world," Mit Sloan Management Review, vol. 56, no. 1, pp. 45-53, 2014.

[17] P. Chatterjee, "Causes and consequences of "order online pick up in-store" shopping behavior," The International Review of Retail, Distribution and Consumer Research, vol. 20, no. 4, pp. 431-448, 2010.

[18] S. Balasubramanian, "Mail versus mall: a strategic analysis of competition between direct marketers and conventional retailers," Marketing Science, vol. 17, no. 3, pp. 181-195, 1998.

[19] F. Bernstein, J.-S. Song, and X. Zheng, "“Bricks-and-mortar” vs. "clicks-and-mortar:" an equilibrium analysis," European Journal of Operational Research, vol. 187, no. 3, pp. 671-690, 2008.

[20] Z. Li, Q. Lu, and M. Talebian, "Online versus bricks-andmortar retailing: a comparison of price, assortment and delivery time," International Journal of Production Research, vol. 53, no. 13, pp. 3823-3835, 2015.

[21] S. Gallino, A. Moreno, and I. Stamatopoulos, "Channel integration, sales dispersion, and inventory management," Management Science, vol. 63, no. 9, pp. 2813-2831, 2017.

[22] D. R. Bell, S. Gallino, and A. Moreno, "Offline showrooms in omnichannel retail: demand and operational benefits," Management Science, vol. 64, no. 4, pp. 1629-1651, 2018.

[23] R. Zhou, Y. Liao, W. Shen, and S. Yang, "Channel selection and fulfillment service contracts in the presence of asymmetric service information," International Journal of Production Economics, vol. 222, Article ID 107504, 2020.

[24] W.-y. K. Chiang, D. Chhajed, and J. D. Hess, "Direct marketing, indirect profits: a strategic analysis of dual-channel supply-chain design," Management Science, vol. 49, no. 1, pp. 1-20, 2003.

[25] K.-Y. Chen, M. Kaya, and Ö. Özer, "Dual sales channel management with service competition," Manufacturing \& Service Operations Management, vol. 10, no. 4, pp. 654-675, 2008.

[26] G. Cai, "Channel selection and coordination in dual-channel supply chains," Journal of Retailing, vol. 86, no. 1, pp. 22-36, 2010.

[27] Y.-W. Zhou, J. Guo, and W. Zhou, "Pricing/service strategies for a dual-channel supply chain with free riding and service- cost sharing," International Journal of Production Economics, vol. 196, no. 196, pp. 198-210, 2018.

[28] L.-B. Oh, H.-H. Teo, and V. Sambamurthy, "The effects of retail channel integration through the use of information technologies on firm performance," Journal of Operations Management, vol. 30, no. 5, pp. 368-381, 2012.

[29] E. Brynjolfsson, Y. J. Hu, and M. S. Rahman, "Competing in the age of Omni-channel retailing," MIT Sloan Management Review, vol. 54, no. 4, p. 23, 2013.

[30] S. Mahar, P. D. Wright, K. M. Bretthauer, and R. P. Hill, "Optimizing marketer costs and consumer benefits across "clicks" and "bricks"," Journal of the Academy of Marketing Science, vol. 42, no. 6, pp. 619-641, 2014.

[31] E. Ofek, Z. Katona, and M. Sarvary, "“Bricks and clicks:” the impact of product returns on the strategies of multichannel retailers," Marketing Science, vol. 30, no. 1, pp. 42-60, 2011.

[32] J. Chen and B. Chen, "Competing with customer returns policies," International Journal of Production Research, vol. 54, no. 7, pp. 2093-2107, 2016.

[33] O. Shy, "Window shopping," 2014.

[34] B. Jing, "Showrooming and webrooming: information externalities between online and offline sellers," Marketing Science, vol. 37, no. 3, pp. 469-483, 2018.

[35] A. Heiman, B. Mcwilliams, and D. Zilberman, "Demonstrations and money-back guarantees: market mechanisms to reduce uncertainty," Journal of Business Research, vol. 54, no. 1, pp. 71-84, 2001.

[36] B. McWilliams, "Money-back guarantees: helping the lowquality retailer," Management Science, vol. 58, no. 8, pp. 1521-1524, 2012.

[37] B. Chen and J. Chen, "When to introduce an online channel, and offer money back guarantees and personalized pricing?" European Journal of Operational Research, vol. 257, no. 2, pp. 614-624, 2017.

[38] Y. Chen and J. Xie, "Online consumer review: word-of-mouth as a new element of marketing communication mix," Management Science, vol. 54, no. 3, pp. 477-491, 2008.

[39] H. Risselada, L. De Vries, and M. Verstappen, "The impact of social influence on the perceived helpfulness of online consumer reviews," European Journal of Marketing, vol. 52, no. 3/ 4, pp. 619-636, 2018.

[40] C. Matt and T. Hess, "Product fit uncertainty and its effects on vendor choice: an experimental study," Electronic Markets, vol. 26, no. 1, pp. 1-11, 2016.

[41] T. Doganoglu, "Switching costs, experience goods and dynamic price competition," Quantitative Marketing and Economics, vol. 8, no. 2, pp. 167-205, 2010.

[42] B. Edelman, S. Jaffe, and S. D. Kominers, "To Groupon or not to Groupon: the profitability of deep discounts," Marketing Letters, vol. 27, no. 1, pp. 39-53, 2016.

[43] Z. Gu and Y. Liu, "Consumer fit search, retailer shelf layout, and channel interaction," Marketing Science, vol. 32, no. 4, pp. $652-668,2013$.

[44] A. Balakrishnan, S. Sundaresan, and B. Zhang, "Browse-andSwitch: retail-online competition under value uncertainty," Production and Operations Management, vol. 23, no. 7, pp. 1129-1145, 2014.

[45] C. Passariello, "In France, a Drive-up Grocery Takes Off-Modifying an Old Model, Online Food Retailer Chrono Drive Drops the Delivery but Keeps the Web Ordering," Wall Street Journal, New York, NY, USA, 2010.

[46] J. Li, L. Yi, V. Shi, and X. Chen, "Supplier encroachment strategy in the presence of retail strategic inventory: centralization or decentralization?" Omega, 2020. 
[47] Y. Liao, A. Diabat, C. Alzaman, and Y. Zhang, "Modeling and heuristics for production time crashing in supply chain network design," Annals of Operations Research, vol. 288, no. 1, pp. 331-361, 2020.

[48] J. Bian, Y. Liao, Y. Y. Wang, and F. Tao, "Analysis of firm CSR strategies,” European Journal of Operational Research, 2020. 